\title{
A Flipped Classroom-Based Education System for College English Teaching
}

\author{
https://doi.org/10.3991/ijet.v14i16.11152 \\ Haiyan Zhang \\ Bengbu Medical College, Anhui, China \\ Zhanghy25@126.com
}

\begin{abstract}
The flipped classroom (FC) is a novel teaching mode combining traditional classroom and computer network technology. This paper attempts to design a FC-based education system for college English teaching, which is critical to the quality of English teaching in colleges. In our research, a college English education system is established based on SQL server and FC. The architecture and functional modules of the system were discussed in details. Specifically, the system architecture was created based on the browser/server (B/S) structure, the data management was realized by SQL server 2008, and the system functions were designed and achieved by JavaServer Pages (JSP). The proposed system was tested in an actual application. The results confirm that the system can meet the teaching demand, arouse the students' interest in learning and improve the effect of English teaching.
\end{abstract}

Keywords - SQL server, flipped classroom (FC), English education system, application effect

\section{Introduction}

With the development of computer, multimedia and network technology, people's learning styles and habits have undergone tremendous changes. The traditional teaching mode can no longer meet the needs of educational informationization. Under this background, the flipped classroom teaching mode came into being. As one of the world's universal languages, English is a compulsory course for colleges and universities. Besides, because of a wide audience, it has developed as the focus of online teaching, which shall provide a necessary technical support for developing the FC teaching mode of college English.

The FC theory was proposed by Eric Mazur of Harvard University, followed by "Woodland Park High School Mode", "Khan Academy Model" and "Riverside Union Mode" [1], which all own special features, and have been widely used. The emergence and promotion of online teaching platforms such as Coursera and Blackboard have promoted the gradual application of the new web-based FC teaching mode in teaching [2]. Although the theoretical and applied research on FCs is relatively mature abroad, it is mainly concentrated on the applied research of science and engineering courses [3], and there have been few research results on the web-based FC teaching 
for liberal arts courses. The FC was introduced to China by scholars in 2012 and attracted wide attention. Different scholars have different attitudes toward the application of FCs in college English teaching. College English FC is a new teaching mode combining traditional classroom and computer network [4]. Wang and Zhang through the analysis of cases and questionnaires discovered that the flipped class can improve students' ability to use English in educational technology [5]. Wan Min conducted research on the micro-class-based FC model, and the results showed that its teaching effect is superior to the traditional teaching mode [6]. In addition, He et al. respectively studied the application of FCs in college English teaching and held a positive attitude towards them [7]. Lu et al. used the questionnaire method to investigate the application effect of the flipped course in junior high school and senior high school English teaching respectively, and found that FC didn't a significant effect on improving the teaching quality and promoting communication between teachers and students [8]. Cheng et al. conducted a questionnaire survey of college English teachers on the implementation of FCs; the results showed that the FCs can improve students' interest and motivation in some ways, but pose major challenges for teachers in terms of time, technology and energy [9]. Based on the literature [10], it's found that the research on FCs is generally increasing year by year, and more people hold a positive attitude towards the application effect of FCs. However, there have been still very few researches on the FC and education system.

Based on the above analysis, this paper designs a FC teaching mode based on college English education system. Then, it analyses various functional requirements of the system, and classifies the system architecture and function modules. For this, the SQL server2008 database platform management system and the JSP were applied to design and implement the dynamic network English education system under the B/S framework. Finally, the questionnaire was conducted to study the application effect of college English education system based on SQL server and FC. The results show that the system can meet the teaching needs, arouse students' enthusiasm for learning, and improve the English teaching effect.

\section{Flipped Classroom Teaching Mode Based on College English Education System}

\subsection{Flipped classroom}

The flipped classroom emerged in the United States in the 1990s. At the beginning, teachers asked students to learn knowledge before class, and think about them after class in order to deepen the students' perception of knowledge; afterwards it developed to the original form of FC that the students watch instructional videos at home, and complete homework in the classroom, then sweeping around the world [11]. Although the definition of FCs has not been unified in the academic world, the basic point of view is the same; that is, FC is the process of reversing the transfer and internalization of knowledge. "Pre-class learning + in-class study" is the main teaching form of FCs, in which the students complete the learning of the knowledge through 
the learning videos produced by the teachers before the class, and the students discuss with the peers and the teachers so that the teachers change from the the knowledgemediator to the knowledge-guider, and the students become the classroom-dominator [12]. Figure 1 shows the structure of classical two-stage FC proposed by Robert Talbert [13], which is the basis of many subsequent FC modes.

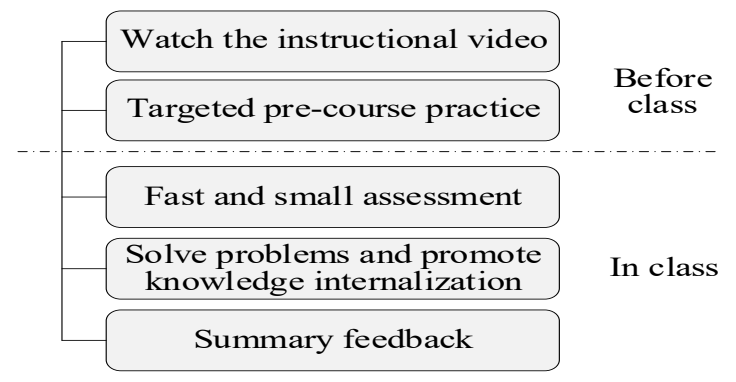

Fig. 1. Robert Talbert's flipped classroom structure

\subsection{Design of flipped classroom teaching mode based on college English edu- cation system}

The previous flipped classroom teaching mode was designed solely for the classroom itself. Most of the teaching materials were published through the WeChat and $\mathrm{QQ}$, and there was no teaching system dedicated to the FC [14]. Based on the FC teaching modes at home and abroad, this paper designs a set of FC teaching mode based on college English education system, and then develops a specialized education system for the FC teaching. Figure 2 shows the FC teaching mode based on the college English education system designed in this paper.

Before-class: Teachers and students complete related tasks through the English education system before class. Teachers are responsible for producing and uploading videos, courseware, cases and other resources related to English learning, arranging student homework, related tests and discussion topics for students to complete knowledge learning before class, while students complete tasks such as homework exercises and online tests after learning relevant teaching resources, understand their learning situation of knowledge, and summarize the problems in the study for online discussions with other students and teachers. The teacher can also understand the students' learning progress by examining their learning and testing results, so as to adjust and formulate the task of discussion learning in class.

In-class: The students report the pre-class learning situation, while the teacher comments on the students' pre-class study and class report, and raises questions to trigger student discussion. Then, the exchanges and discussions are made between the students and between the students and teacher, so that the teachers can make supplementary explanation according to the progress of the discussion, and students deepen their understanding of the problem and continue to explore. Finally, the teacher answers questions to the students and summarizes the knowledge points of this lesson, and arranges homework. 


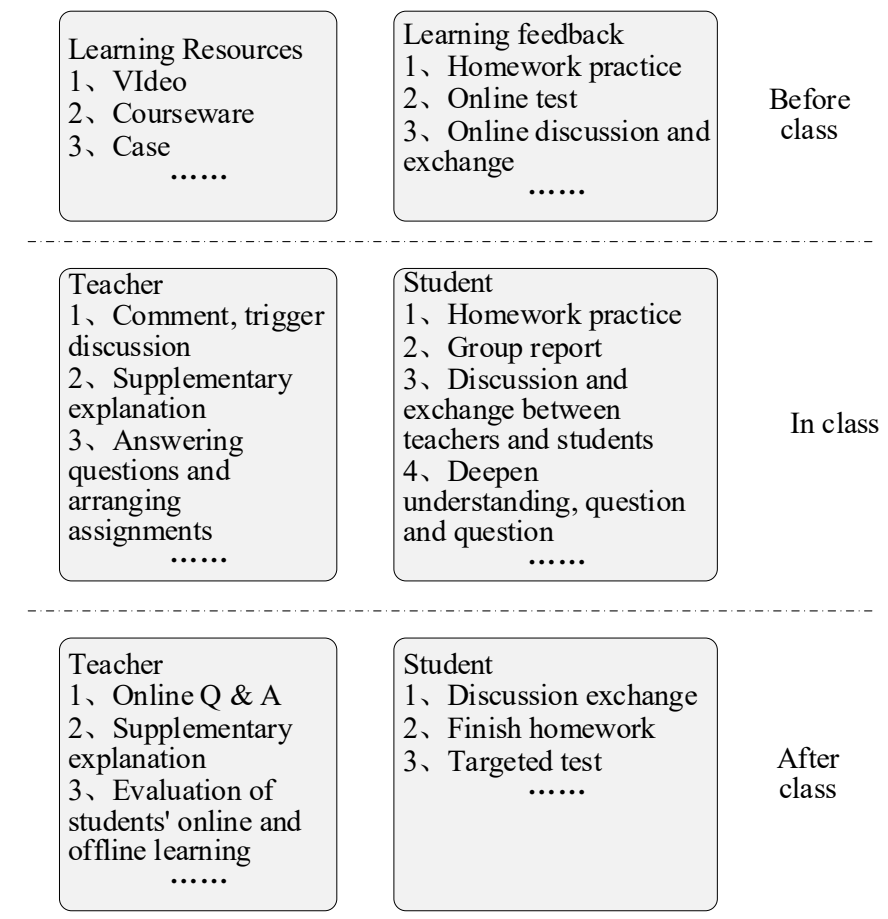

Fig. 2. Flipped classroom teaching mode based on college English education system

After-class: Through the English education system, teachers conduct discussion and exchanges with students, answer questions online, and evaluate students' online and offline learning. Students complete homework assignments and conduct targeted tests based on their own learning.

\section{Development and Application of College English Education system Based on SQL Server and Flipped Classroom}

\subsection{System requirements analysis}

From the flipped classroom teaching mode based on the college English education system mentioned above, the teachers and students are the main users of the system, and in order to ensure the normal and stable operation, the system maintenance is required by the system administrator. The main functions of the teacher user module include teaching management, courseware management, database management and class teaching; those of the student user include Q\&A and class discussions, viewing learning records, online learning, online testing, and completing assignments. The primary responsibility of the system administrator is to manage the user's information, teaching resources, and forums. Figure 3 shows the system function structure diagram according to the requirements of each user role. 


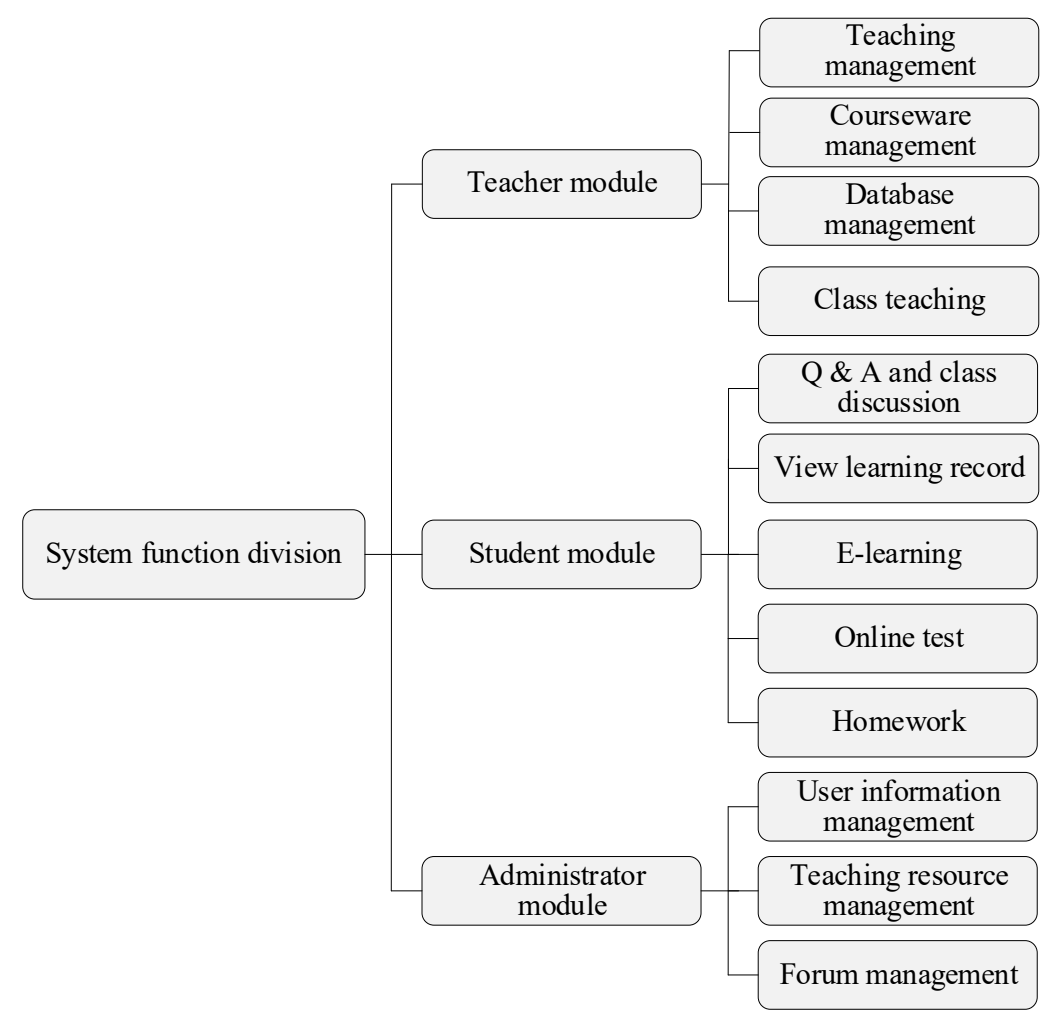

Fig. 3. System function division

\subsection{Overview of system theory and technology}

SQL server: SQL server is a relational data management system. Based on improvement and innovation of SQL server 2005, SQL server 2008 is developed, which can provide reports, queries, search and other data requirements, as an efficient, secure, intelligent database platform that can basically meet all the needs of users. [15]. SQL server 2008 can directly encrypt log files, data files and the entire database without changing the application, providing a comprehensive solution for encryption and key management by hardware security module (HSM) products and third-party key management. To improve compliance and security, it also provides data review and a more reliable database mirroring platform for the users [16].

JSP technology: Java Server Pages (JSP) technology [17] a dynamic web page technology standard. Like Servlet, it is executed on the server side, and the running result is directly transmitted to the client browser, so the client can browse only with a browser. The advantages of JSP lie in generating reusable components, identifying simplified page development process, separating content generation and display, support of multi-platform development, and strong scalability. 


\subsection{System design and implementation}

Physical deployment for college English education system: In order to reduce the loss of data transmission, and not affect the use of other location data in case of the network failure or partial data damage, this paper uses multi-layer distributed deployment, as shown in Figure 4.
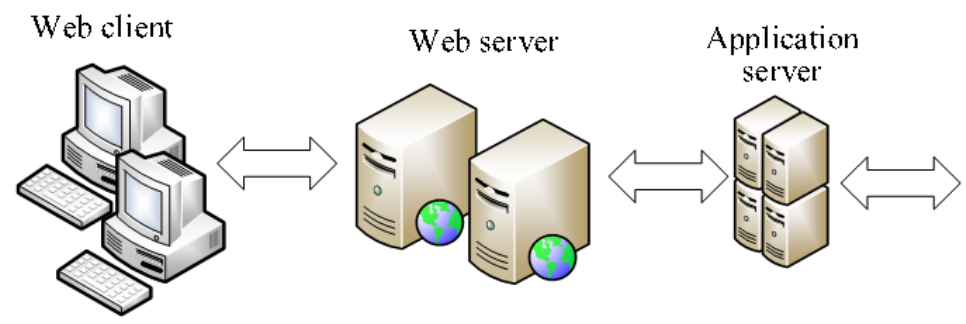

Database

Fig. 4. Structure diagram of distributed deployment

Design and implementation of partial functional modules in college English education system

Teacher function module: Teachers create classes, publish teaching resources, course assignments and course announcements, submit test questions and related standards, conduct online communication with students, review student assignments, view student test scores and learning, and understand student learning status for timely course adjustment through the teacher function module. Figure 5 shows the teacher's courseware operation interface.

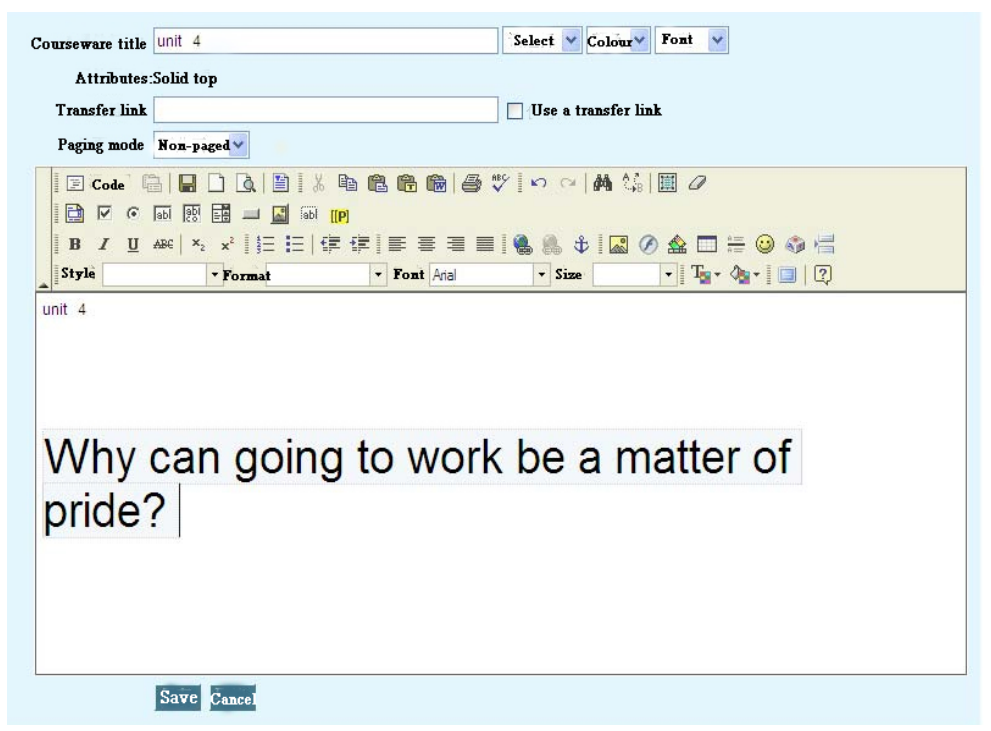

Fig. 5. Teacher release courseware operation interface 
Student function module: The main student module functions are for the students to register and log in, download online or download the course resources provided by the teacher for them to choose the appropriate time, place and progress according to their own conditions, and exchange knowledge and learning with teachers and other students. It can also provide online test function to facilitate students' learning effect detection. Figure 6 shows the video playback interface, and Figure 7 shows the online test interface.

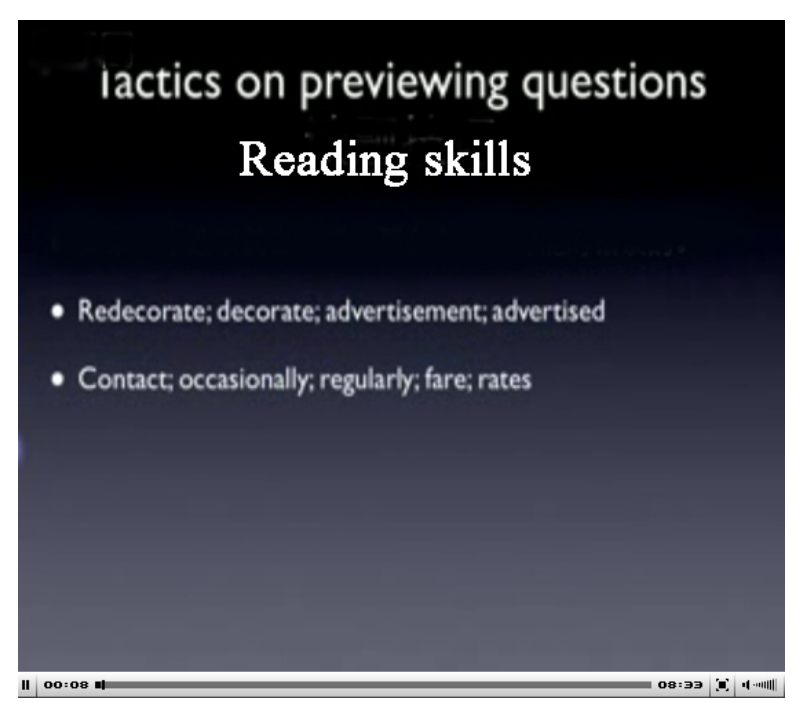

Fig. 6. Video playback interface

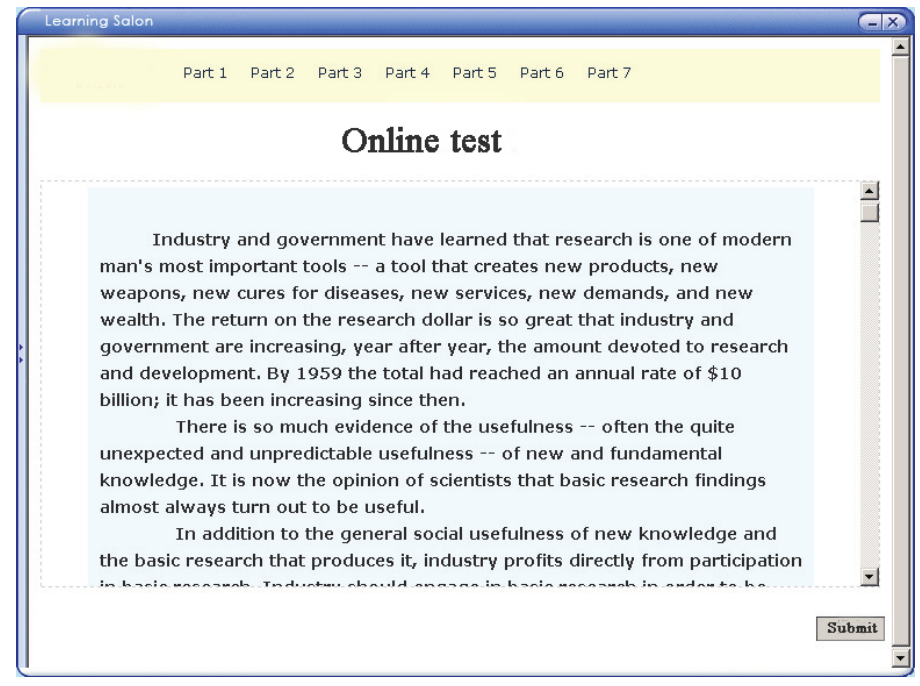

Fig. 7. Student online test interface 


\subsection{Application effect of college English education system based on SQL serv- er and flipped classroom}

In this study, 152 sophomore students from non-English majors in a university in Zhejiang were selected as the research object. These students conducted college English learning in the FC mode based on the college English education system for two semesters. Afterwards, questionnaire survey was conducted on the actual application effect of the education system college English based on SQL server and FC. The specific results are as follows:

Teaching effects: In the survey on the teaching effect of this system, $72 \%$ students think that it's better or very good; $5 \%$ were uncertain; no students indicated that the teaching effect is poor, as shown in Figure 7.

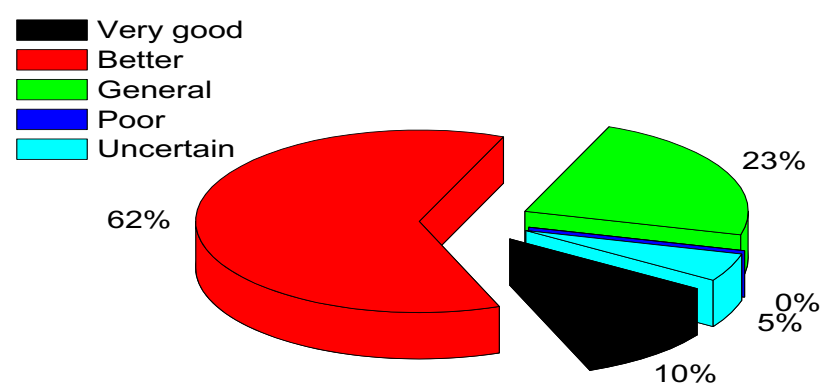

Fig. 8. Teaching effect survey results

Students' self-learning: From the survey results of the students' self-learning situation in Figure 7, most students believe that the use of this system can promote their active awareness, learning interest, independence problem solving skills and selfmonitoring capabilities.

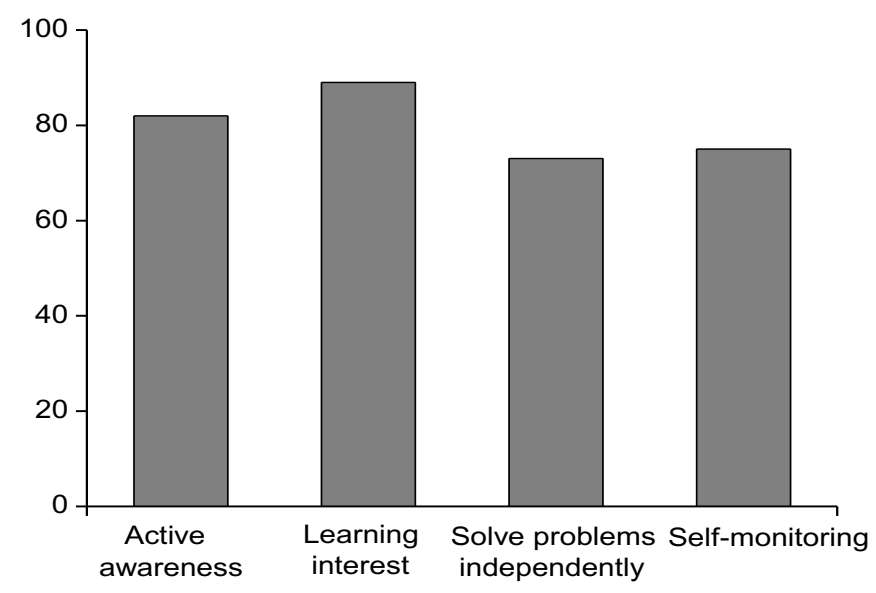

Fig. 9. Student self-learning survey results 


\section{Conclusion}

This paper focuses on the development and application of college English education system based on SQL server and FC. The specific conclusions are as follows:

- Based on the FC teaching modes at home and abroad, a set of FC-based teaching mode based on college English education system was designed.

- According to the FC teaching mode, the architecture and functional modules of the college English education system were determined. Specifically, the system architecture was created based on the browser/server $(\mathrm{B} / \mathrm{S})$ structure, the data management was realized by SQL server 2008, and the system functions were designed and achieved by JavaServer Pages (JSP).

- Using the questionnaire method, the application effect of college English education system based on SQL server and FC was explored. The results show that the system can meet the teaching needs, arouse the students' interest in learning, and improve the effect of English teaching

\section{Acknowledgement}

Foundation item: Project name: A Study on the Applying Bibliotherapy in English Initiation Story Courses to Prevent Psychological Diseases of College Students; This article is a key project of Humanities and Social Sciences in Bengbu Medical College (BYKY17131skZD).

\section{References}

[1] Templeton, S. (1991). Teaching and learning the English spelling system: reconceptualizing method and purpose. The Elementary School Journal, 92(2): 185-201. https://doi.org/ $10.1086 / 461687$

[2] Lang, Y. (2008). World Englishes: implications for international communication and English language teaching by kirkpatrick, andy. Modern Language Journal, 92(4): 654-655. https://doi.org/10.1111/j.1540-4781.2008.00793 13.x

[3] Warschauer, M., Shetzer, H., Meloni, C. (2000). Internet for English teaching. System, 29(3): 419-426 http://dx.doi. org/10.1016/s0346-251x(01)00021-5

[4] Pica, T. (2000). Tradition and transition in English language teaching methodology 1. System, 28(1): 1-18. https://doi.org/10.1016/s0346-251x(99)00057-3

[5] Li, D., Edwards, V. (2014). English language teaching and educational reform in western china: a knowledge management perspective. System, 47: 88-101. https://doi.org/10.1016/ j.system.2014.09.019

[6] Wu, W. C. V., Wang, R. J., Chen, N. S. (2015). Instructional design using an in-house built teaching assistant robot to enhance elementary school English-as-a-foreign-language learning. Interactive Learning Environments, 23(6): 696-714. https://doi.org/10.1080/ 10494820.2013 .792844

[7] Bricault, D. (2015). Blended learning in English language teaching: course design and implementation briantomlinson and clairewhittaker (eds.). London, England: British council, 2013. pp. 252. TESOL Quarterly, 49 (1): 210-212. https://doi.org/10.1002/tesq.215

[8] Moffett \& Jennifer. (2015). Twelve tips for "flipping" the classroom. Medical Teacher, 37(4): 331-336. https://doi.org/10.3109/0142159x.2014.943710 
[9] Dong, C., Sharma, N. (2015). Flipping the classroom with adaptive learning technology. Medical Teacher, 37(10): 1. https://doi.org/10.3109/0142159x.2015.1045846

[10] Boyd, G., Keller, A., Kenner, R. (1982). Remedial and second language english teaching using computer assisted learning. Computers \& Education, 6(1): 105-112. https://doi.org/10.1016/0360-1315(82)90019-7

[11] Demaiziere, F. (1982). An experiment in computer assisted learning of english grammar at the university of paris vii. Computers \& Education, 6(1): 121-125. https://doi.org/10.1 016/0360-1315(82)90022-7

[12] Tamburini, F. (1999). A multimedia framework for second language teaching in selfaccess environments. Computers \& Education, 32(2): 137-149. https://doi.org/10.1016/ s0360-1315(98)00061-X

[13] Diab, H. B., Demashkieh, I. (1991). A computer-aided teaching package for microprocessor systems education. IEEE Transactions on Education, 34(2): 179-183 https://doi.org/ $\underline{10.1109 / 13.81598}$

[14] Elian, S.A., Hamaidi, D.A. (2018). The effect of using flipped classroom strategy on the academic achievement of fourth grade students in Jordan, International Journal of Emerging Technologies in Learning, 13(2): 110-125. https://doi.org/10.3991/ijet.v13i02.7816

[15] Rong, R. (2014). Research on web site construction of quality course based on network teaching platform. International Journal of Technology Management, 89-92 https://doi.org/10.2495/gen 130501

[16] Wong, L. H., Chai, C. S., Zhang, X., King, R. B. (2015). Employing the tpack framework for researcher-teacher co-design of a mobile-assisted seamless language learning environment. IEEE Transactions on Learning Technologies, 8(1): 31-42. https://doi.org/10.1109/ tlt.2014.2354038

[17] Rasi, P., Hautakangas, M., Vayrynen, S. (2015). Designing culturally inclusive affordance networks into the curriculum. Teaching in Higher Education, 20(2): 131-142 https://doi. org/10.1080/13562517.2014.957268

\section{$7 \quad$ Author}

Haiyan Zhang is member of teaching staff of Bengbu Medical University, 2600 Road Donghai, Bengbu, Anhui, China. She is the Associate Edior of Autonomous Learning Tutorial 2 of College English. (Chongqing University Press) She won awards in some teaching competitions. (The second runner-up in FLTRP Star Teacher Contest, the second prize in Young Teachers' Basic Teaching Skills Contest of Bengbu Medical University).

Article submitted 2019-05-29. Resubmitted 2019-07-12. Final acceptance 2019-07-12. Final version published as submitted by the authors. 